\title{
PENGUJIAN POTENSI ANTIJAMUR EKSTRAK AIR KAYU SECANG TERHADAP Aspergillus niger DAN Candida albicans
}

\author{
Yenni Karlina ${ }^{1, *}$, Putranti Adirestuti ${ }^{1}$, Dewi Meliati Agustini $^{2}$, Nurul Laily Fadhillah $^{1}$, Nida \\ Fauziyyah $^{1}$, Desi Malita ${ }^{2}$ \\ ${ }^{1}$ Fakultas Farmasi, Universitas Jenderal Achmad Yani, Cimahi \\ ${ }^{2}$ Jurusan Kimia, Fakultas MIPA, Universitas Jenderal Achmad Yani, Cimahi \\ *Alamat Korespondensi: yheyhen_k@yahoo.co.id
}

\begin{abstract}
Abstrak: Khasiat kayu secang sebagai minuman sudah banyak dikenal. Beberapa contoh penggunaan secara empiris adalah untuk mengatasi nyeri akibat gangguan sirkulasi darah, penawar racun bagi tubuh, antiseptik, antibakteri dan antikoagulan. Semua khasiat tersebut terkait dengan metabolit sekundernya, antara lain flavonoid, polifenol, terpenoid dan tanin yang membuat kayu secang memiliki aktivitas antibakteri. Pada penelitian sebelumnya diketahui fraksi metanol, ekstrak dan fraksi etanol dari kayu secang, menunjukan aktivitas antibakteri. Berdasarkan alasan tersebut, telah dilakukan penelitian tentang uji potensi kayu secang terhadap pertumbuhan Aspergillus niger dan Candida albicans. Ekstraksi dilakukan dalam pelarut air (mineral kemasan, $\mathrm{pH} 3,0$ dan $\mathrm{pH} 7,0$ ); pada suhu $60^{\circ} \mathrm{C}$ selama 30 menit. Mikroorganisme uji adalah Aspergillus niger dan Candida albicans. Potensi antimikroba diukur berdasarkan daya hambat pada kedua mikroba uji dengan metode difusi perforasi. Hasil penelitian menunjukkan ekstrak air $\mathrm{pH} 3,0$ dengan konsentrasi $20 \%$ mampu menghambat kapang dan khamir dengan diameter 9,69 dan 9,42 $\mathrm{mm}$. Metabolit berupa flavonoid dan terpenoid diduga yang berperan dalam hal ini.
\end{abstract}

Kata kunci: Secang, ekstrak, flavonoid, antimikroba

\begin{abstract}
Efficacy of sappan wood as the drinks are well-known. Some examples of the use of empirically is to overcome the pain caused by disorders of blood circulation, detoxifying the body, antiseptic, antibacterial and anticoagulant. All these properties associated with secondary metabolites, including flavonoids, polyphenols, terpenoids and tannins. Allegedly this is what makes sappan wood antibacterial activity. In previous studies the fraction of methanol, ethanol extracts and fractions of a sappan wood, showed antibacterial activity. Based on these reasons, has conducted research on sappan wood potency test on the growth of Aspergillus niger and Candida albicans. Extraction is done by using the solvent water (bottled mineral, pH 3.0 and pH 7.0); at $60^{\circ} \mathrm{C}$ for 30 minutes. The test microorganism is Aspergillus niger and the yeast Candida albicans. The antimicrobial potency was measured based on both microbial inhibition test with perforations diffusion method. The results showed the water extract pH of 3.0 with a $20 \%$ concentration able to inhibit molds and yeasts with a diameter of 9.69 and $9.42 \mathrm{~mm}$. Metabolites in the form of flavonoids and terpenoids thought to play a role in this regard.
\end{abstract}

Keywords: Sappan wood, extract, flavonoid, antimicrobe

\section{PENDAHULUAN}

Kayu secang (Caesalpinia sappan L.) termasuk suku Caesalpiniaceae tersebar di Indonesia, nama lainnya yaitu: cang (Bali), sepang (Sasak), kayu sena (Manado), naga, sapang (Makasar), soga jawa (Jawa), kayu secang (Madura), secang (Sunda), seupeung, sopang, cacang (Sumatra), sepang (Bugis), sawala, hinianga, sinyhiaga, singiang (Halmahera Utara), sepen (Halmahera Selatan), lacang (Minangkabau), sepel (Timor), hape (Sawu), hong (Alor) (Hariana, 2006). Kayu secang sudah sejak zaman dahulu digunakan sebagai minuman yang memberikan efek rasa hangat pada tubuh. Awalnya ia hanya minuman keraton, dinikmati oleh keluarga bangsawan saja. Kayu secang juga memberikan warna yang menarik sehingga bisa digunakan sebagai pewarna alami. Kayu secang mengandung fenolik, flavonoid, tanin, polifenol, kardenolin, antrakinon, sappan chalcone, caesalpin, resin, resorsin, brazilin, d-alfa phallandren, oscimenen, dan minyak atsiri.
Selain itu, tanaman secang merupakan salah satu tanaman yang digunakan sebagai pigmen alami. Bagian tanaman secang yang sering digunakan adalah kayu. Kayu secang menghasilkan pigmen berwarna merah. Pigmen merah ini disebut antosianin yang bersifat mudah larut dalam air panas. Penelitian Maharani (2003) menunjukkan bahwa pigmen alami kayu secang dapat dipengaruhi sinar UV, oksidator, suhu dan $\mathrm{pH}$. Pigmen warna alami dipengaruhi oleh $\mathrm{pH}$, pada suasana asam pigmen berwarna kuning sampai jingga dan pada suasana basa pigmen berwarna merah sampai merah keunguan. Pengaruh suhu dapat menyebabkan pigmen kayu secang mengalami degradasi warna

Tanaman secang secara tradisional dapat dimanfaatkan untuk pengobatan diare, disentri, batuk darah pada TBC, muntah darah, sifilis, malaria, tetanus, pembengkakan (tumor), dan nyeri karena gangguan sirkulasi darah. Penelitian lain menunjukkan bahwa fraksi etanol kayu secang menunjukkan daya antibakteri lebih baik 
dibandingkan fraksi air kayu secang terhadap Proteus vulgaris, coliform dan dipthheroid, sedangkan fraksi eter minyak tanah dan fraksi kloroform tidak memiliki daya antibakteri (Diansari, 2009). Fraksi metanol secang dapat menghambat pertumbuhan Mycobacterium tubercolosis $\mathrm{H} 37 \mathrm{Rv}$ dengan nilai KBM sebesar $1 \%$. Hasil kromatografi lapis tipis menunjukkan adanya senyawa terpenoid, flavonoid dan antrakinon (Ayuningtyas, 2009).

Kayu secang memiliki banyak manfaat yang digunakan secara empiris. Oleh karena itu, perlu dilakukan pengujian dengan pendekatan ilmiah. Pengujian potensi ekstrak air kayu secang terhadap pertumbuhan jamur Aspergilus niger dan Candida albicans merupakan penelitian yang dilakukan sebagai sumber informasi bagi penelitian selanjutnya berdasarkan penelitian sebelumnya tanaman ini berkhasiat sebagai antifungi.

\section{BAHAN DAN METODE}

Alat dan Bahan

Alat-alat yang digunakan dalam penelitian ini adalah timbangan analitik (Sartorius BL 2105), mikroskop, seperangkat alat gelas yang digunakan untuk penelitian, cawan petri, kaki tiga, kassa, rak tabung reaksi, spatel logam, pipet tetes, krus silika, kompor pengarang, tanur, penangas air, alat destilasi, oven (Memmert), deksikator, pipet media, plat tetes, bunsen, botol semprot, cawan penguap, mortir dan stamper, autoklaf, kawat ose, inkubator, lemari es, dan mikropipet.

Bahan yang digunakan dalam penelitian ini adalah tanaman Secang, air suling, asam sitrat anhidrat, natrium sitrat dihidrat, kalium dihidrogenfosfat, amonia encer, kloroform, asam klorida $2 \mathrm{~N}$, amil alkohol, kalium hidroksida 5\%, etanol 95\%, toluen, kloroform, pereaksi Mayer, pereaksi besi (III) klorida, pereaksi Dragendorff, pereaksi Liebermann Burchard, pereaksi vanillinasam sulfat, kloralhidrat, natrium hidroksida, larutan gelatin $1 \%$, eter, kertas saring, kertas saring bebas abu, alumunium foil, Potato Dextrose Agar (PDA).

\section{Subjek Penelitian}

Subjek penelitian adalah mikroba $A$. niger dan $C$. albicans yang dapat dihambat pertumbuhannya oleh ekstrak air kayu secang pada pH 3,0 dan $\mathrm{pH}$ 7,0.

\section{Pembuatan Ekstrak}

Bahan yang digunakan yaitu simplisia kayu secang yang diekstraksi dalam pelarut air pada suhu $60^{\circ} \mathrm{C}$ selama 30 menit dilakukan pada $\mathrm{pH} 3,0$ dan $\mathrm{pH}$ 7,0 . Filtrat disaring dengan kain blacu dan disaring kembali dengan kertas saring. Filtrat diuapkan dalam penangas air sampai volumenya berkurang. Filtrat dikeringbekukan.

\section{Penapisan Fitokimia}

Pada penelitian ini dilakukan penapisan fitokimia terhadap simplisia, ekstrak air kayu secang pada $\mathrm{pH}$
3,0 dan pH 7,0 yang sudah diperolah. Penapisan fitokimia yang dikerjakan meliputi pemeriksaan kandungan alkaloid, polifenol, tannin, monoterpenoid, seskuiterpenoid, flavonoid, saponin, kuinon, steroid dan triterpenoid.

\section{Stabilitas Fisik Zat Warna}

Pengujian stabilitas fisik zat warna kayu secang terdiri dari $\mathrm{pH}$, Warna visual dan nilai serapan radiasinya. Stabilitas warna di amati 7 hari dengan pengamatan yang dilakukan setiap hari. Pengukuran $\mathrm{pH}$ dilakukan menggunakan $\mathrm{pH}$ universal, warna diamati secara langsung untuk melihat ada atau tidaknya perubahan warna selama penyimpanan dan nilai serapan dilakukan menggunakan alat Spektofotometer UV-VIS pada panjang gelombang dengan rentang 400 sampai $800 \mathrm{~nm}$. Nilai serapan yang tetap selama penyimpanan dianggap bahwa zat warna dari kayu secang stabil secara fisik.

\section{Penentuan aktivitas antijamur}

Pengujian aktivitas antijamur dilakukan dengan metode difusi agar perforasi, caranya cawan Petri yang telah berisi $15 \mathrm{ml}$ media PDA dibiarkan memadat. Setelah padat dibuat sumur difusi masingmasing sebanyak 4 buah pada setiap petri dengan menggunakan cork borer. Setiap sumur difusi diisi dengan $50 \mu \mathrm{l}$ ekstrak uji. Diameter hambat yang terbentuk untuk masing-masing pengujian diukur dengan jangka sorong. Pengujian untuk setiap konsentrasi yang sama dilakukan sebanyak tiga kali. Parameter yang digunakan sebagai acuan untuk mendapatkan aktivitas ekstrak terhadap mikroorganisme uji adalah besarnya diameter hambat, yaitu antara 14-16 mm, konsentarasi terkecil dari ekstrak yang dapat menunjukkan diameter hambat seperti diatas disebut sebagai konsentrasi hambat minimum (KHM) (Collins \& Lyne 1970).

\section{HASIL DAN PEMBAHASAN}

\section{Hasil ekstraksi dan penapisan fitokimia}

Hasil ekstraksi secang dan penapisan fitokimianya ditampilkan pada Tabel 1. Penapisan fitokimia terhadap simplisia menunjukkan bahwa kayu secang mengandung alkaloid, flavonoid, polifenol, monoterpen dan seskuiterpen. Ekstrak air secang $\mathrm{pH} 3$ dan $\mathrm{pH} 7$ pada penapisan fitokimia menunjukkan adanya kandungan flavonoid. Kandungan metabolit sekunder, seperti monoterpen dan seskuiterpen hanya ada pada ekstrak air secang pH 3, sedangkan pada ekstrak air secang $\mathrm{pH} 7$ juga mengandung alkaloid dan tanin.

Penelitian Saravanakumar \& Chandra (2013) menunjukkan bahwa ekstrak metanol dan ekstrak etanol dari $C$. sappan $\mathrm{L}$ memiliki kandungan kimia antara lain flavonoid, fenolik, tanin dan saponin. Penapisan fitokimia juga telah dilakukan terhadap ekstrak air, etanol dan petroleum eter dari kayu secang. Ekstrak airnya memiliki kandungan kimia tanin dan fenol (Srinivasan et al. 2012). 
Tabel 1. Hasil telaah fitokimia dari kayu secang

\begin{tabular}{lccc}
\hline \begin{tabular}{l} 
JENIS SENYAWA \\
\multicolumn{1}{c}{ METOBOLIT }
\end{tabular} & SIMPLISIA & $\begin{array}{c}\text { EKSTRAK } \\
\text { AIR }\end{array}$ & $\begin{array}{c}\text { EKSTRAK } 3,0 \\
\text { AIR pH 7,0 }\end{array}$ \\
\hline Alkaloid & + & - & + \\
Flavonoid & + & + & + \\
Kuinon & - & - & - \\
Monoterpen & + & + & - \\
\& seskuiterpen & + & - & - \\
Polifenol & - & - & - \\
Saponin & - & - & - \\
Steroid \& triterpenoid & - & - & + \\
Tanin & - & & \\
\hline Kan & & & \\
\hline
\end{tabular}

Keterangan :

- $\quad$ : menunjukkan tidak ada terdeteksi senyawa yang di uji

+ : menunjukkan ada terdeteksi senyawa yang di uji

Tabel 2. Pengujian potensi ekstrak air kayu secang

\begin{tabular}{|c|c|c|c|}
\hline \multirow[t]{2}{*}{ EKSTRAK } & \multirow{2}{*}{$\begin{array}{c}\text { KONSENTRASI } \\
(\%)\end{array}$} & \multicolumn{2}{|c|}{$\begin{array}{l}\text { DIAMETER HAMBAT PADA } \\
\text { PERTUMBUHAN MIKROBA } \\
(\mathrm{mm}) \\
\end{array}$} \\
\hline & & $\begin{array}{c}\text { Aspergillus } \\
\text { niger }\end{array}$ & $\begin{array}{l}\text { Candida } \\
\text { albicans }\end{array}$ \\
\hline \multirow{7}{*}{$\begin{array}{l}\text { Air mineral } \\
\text { pH 7,0 }\end{array}$} & 5 & - & - \\
\hline & 10 & - & - \\
\hline & 15 & - & - \\
\hline & 20 & 8,07 & 9,4 \\
\hline & 40 & 9,05 & - \\
\hline & 60 & 9,07 & - \\
\hline & 80 & 10,38 & - \\
\hline \multirow{7}{*}{$\begin{array}{l}\text { Air dengan } \\
\mathrm{pH} 3,0\end{array}$} & 5 & - & - \\
\hline & 10 & - & - \\
\hline & 15 & - & - \\
\hline & 20 & 9,69 & 9,42 \\
\hline & 40 & 9,7 & 9,72 \\
\hline & 60 & 9,02 & - \\
\hline & 80 & 8,71 & - \\
\hline \multirow{7}{*}{$\begin{array}{l}\text { Air dengan } \\
\mathrm{pH} 7,0\end{array}$} & 5 & - & - \\
\hline & 10 & - & - \\
\hline & 15 & - & - \\
\hline & 20 & 9,05 & 8,03 \\
\hline & 40 & 9,06 & 9,74 \\
\hline & 60 & 9,71 & - \\
\hline & 80 & 9,01 & - \\
\hline
\end{tabular}

Penapisan fitokimia yang dilakukan ekstrak air secang dengan kedua $\mathrm{pH}$ yang berbeda ini memberikan kenyataan bahwa kayu secang mempunyai aktivitas biologi khususnya antimikroba. Senyawa yang diduga memiliki aktivitas antimikroba adalah flavonoid dan terpenoid.

\section{Uji aktivitas antimikroba}

Konsentarasi bahan uji terkecil yang mampu memberikan hambatan disebut dengan konsentrasi
Hambat Minimum (KHM) (Puspadewi dkk. 2013). Hasil uji ekstrak air mineral dengan $\mathrm{pH} \quad 7$ menunjukkan nilai KHM (Konsentrasi Hambat Minimum) 20\% terhadap C. albicans dan A. niger. Pengujian juga dilakukan dengan menggunakan ekstrak air secang dengan $\mathrm{pH} \quad 3$ dan $\mathrm{pH} \quad 7$ menunjukkan KHM masing-masing $20 \%$ terhadap C. albicans dan A. niger. Hasil pengujiannya dapat dilihat pada Tabel 2. Pengujian aktivitas antimikroba air kayu secang ini menunjukkan adanya hambatan 
berupa zona bening di sekitar lubang perforasi pada bahan uji. Ukuran diameter zona bening ini menunjukkan besarnya aktivitas dari bahan uji.

Hasil pengujian ini sejalan dan relevan dengan penelitian yang dilakukan oleh Mohan et al. (2011) yang menunjukkan adanya aktivitas antimikroba dari ekstrak air dan etanol C. sappan and Mimosa pudica L terhadap Staphylococcus aureus, Bacillus subtilis, Escherichia coli, Pseudomonas aeruginosa, Klebsiella pneumonia, Proteus vulgaris, Candida albicans dan Aspergillus niger. Penelitian aktivitas antimikroba juga dilakukan oleh Srinivasan et al. (2012) dari ekstrak etanol, petroleum eter dan air $C$. sappan terhadap Salmonella typhi, Streptococcus faecalis, E. coli, Enterobacter aerogenosa, $P$. aerogenosa, S. aureus, A. niger, dan C. albican.

\section{KESIMPULAN}

Ekstrak air kayu secang memiliki potensi sebagai antijamur. Ekstrak air kayu secang mampu menghambat $A$. niger dan $C$. albicans. Pada penelitian ini uji ekstrak air kayu secang menunjukkan nilai KHM masing-masing $20 \%$.

\section{DAFTAR PUSTAKA}

Ayuningtyas, P. (2009). Uji aktivitas antibakteri fraksi kloroform ekstrak etanol kayu Secang (Caesalpinia sappan L.) terhadap Staphylococcus aureus dan Shigella dysentriae serta bioautografinya. Skripsi. Surakarta: Fakultas Farmasi Universitas Muhammadiyah.
Collins, H.C. \& Lyne, M.P. (1970). Microbiological Methods, $3^{\text {rd }}$ edition. University Park Press: Baltimore.

Hariana, A. (2006). Tumbuhan obat dan khasiatnya. Penebar Swadaya: Jakarta.

Maharani, K. (2003) Stabilitas pigmen Brazilin Pada kayu Secang (Caesalpina sappan L.). Skripsi. Bogor: Fakultas Teknologi Pertanian, Institut Pertanian Bogor.

Mohan, G., Anand, S.P. \& Doss, A. (2011). Efficacy of aqueous and methanol extracts of Caesalpinia sappan L. and Mimosa pudica L. for their potential antimicrobial activity. South Asia Journal of Biological Scences. 1(2): 4857.

Puspadewi, R., Adirestuti, P. \& Menawati, R. (2013). Khasiat umbi bawang dayak (Eleutherine palmifolia (I.) Merr.) sebagai herbal antimikroba kulit. Kartika Jurnal Ilmiah Farmasi. 1(1): 31-37.

Saravanakumar, S. \& Chandra, J.H. (2013). Screening of antimicrobial activity and phytochemical analysis of Caesalpinia sappan L. Journal of Chemical and Pharmaceutical Research. 5(2): 171-175.

Srinivasan, R., Selvam, G.G., Karthik, S., Mathivanan, K., Baskaran, R., Karthikeyan, M., Gopi, M. \& Govindasamy, C. (2012). In vitro antimicrobial activity of Caesalpinia sappan L. Asian Pacific Journal of Tropical Biomedicine. 2(1): S136-S139. 